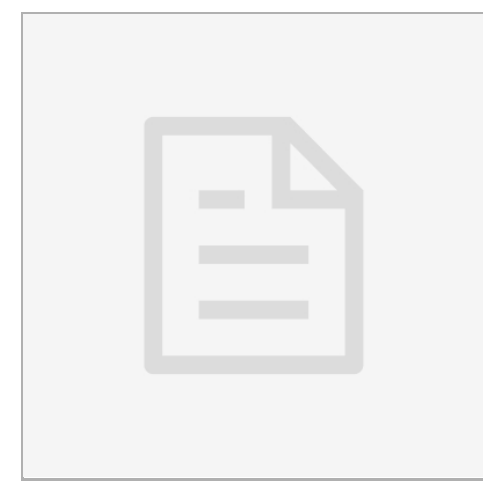

VERSION 3

NOV 05, 2017

OPEN ӘACCESS

DOI:

dx.doi.org/10.17504/protocol s.io.khfct3n

Protocol Citation: Tianshun Yan, Yanyong Zhao, Shuanghua Luo 2017. A second-order jump diffusion model with application to stock market returns. protocols.io

https://dx.doi.org/10.17504/p rotocols.io.khfct3n

License: This is an open access protocol distributed under the terms of the Creative Commons Attribution License, which permits unrestricted use, distribution, and reproduction in any medium, provided the original author and source are credited

Protocol status: Working

Created: Oct 28, 2017

Last Modified: Feb 20, 2018

PROTOCOL integer ID:

8455

\section{(3) A second-order jump diffusion model with application to stock market returns V.3}

Tianshun Yan ${ }^{1}$, Yanyong Zhao ${ }^{2}$, Shuanghua Luo ${ }^{3}$

${ }^{1} X i$ 'an Jiaotong University; ${ }^{2}$ Nanjing Audit University;

${ }^{3}$ Xi'an Polytechnic University

Tianshun Yan

\section{ATTACHMENTS \\ Table 1.pdf fig1.pdf Table 2.pdf Table 3.pdf Table 4.pdf}


Keywords: second-order jump diffusion model, maximum likelihood estimation, stock market returns.

\section{A NEW MODEL FOR STOCK MARKET RETURNS}

1 create a new second-order jump diffusion, in which the drift is clearly linear, the diffusion is a convex function and possion jump.

\section{ESTIMATION OF MODEL}

2 construct maximum likelihood estimation of the model in order to obtain the coefficient estimators using sequential quadratic programming with the "fmincon" routine embedded in the optimization toolbox of Matlab.

\section{A FORMAL STATISTICAL TEST FOR THE PRESENCE OF JUMPS}

3 employ the likelihood ratio test statistic for testing the presence of jumps in thestock and stock index returns.

\section{MONTE CARLO SIMULATION STUDY}

4 conduct a monte carlo simulation experiment for the new second order diffusionmodel aimed at evaluating the performance of our estimation approach. Here, we generate 100replications (paths) of dataset according to our design with each replicationconsisting of $(n=2520)$ observations.

Dataset

simulated data $\{X\}$ 


\section{EMPIRICAL ANALYSIS ON REAL-WORLD DATA}

5 empirical analysis of stock market data from America, Asia and Europe. As an example, the Microsoft stock log-price and returns are provided. Other stocks have similar statistical characterization; obtain the parameter estimates of the proposed models for the stocks and stock indexes.

\section{Dataset}

stocks 